\title{
Lap weld joint modelling and simulation of welding in programme SYSWELD
}

\author{
Radoslav Koňár ${ }^{1, *}$, Miloš Mičian ${ }^{1}$, Andrej Zrak ${ }^{1}$ \\ ${ }^{1}$ University of Žilina in Žilina, Faculty of Mechanical Engineering, Univerzitná 1, 01026 Žilina, \\ Slovakia
}

\begin{abstract}
Simulations of the welding process for applications of practice using SYSWELD are presented. This paper presents simulation of welding in the repair of high-pressure gas pipeline with steel sleeve with composite filling. Material of experimental sample was steel S355. The simulations in SYSWELD divided in to two parts: the thermal simulation followed by the mechanical simulation. The results of the numerical model, which are listed in article are compared to real experiments.
\end{abstract}

Keywords: Welding simulation, SYSWELD, lap joint, steel S355

\section{Introduction}

Simulation tools will continue to gain importance for both scientific investigations and industrial applications. This further applies to welding technology. The present work focuses on the simulation of temperature fields, structural changes, residual stresses, distortions and hardness due to the welding of the circumferential overlap weld joint at the repair of the gas pipeline by composite sleeve.

\section{Permanent repair of defects at gas pipelines with using steel sleeve}

External corrosion is a major concern for pipeline operators. When areas of corrosion or other damage on operating pipelines are identified, there are significant economic and environmental incentives for performing repair without removing the pipeline from service. There are a variety of repair strategies available to pipeline operators for a given repair situation. One way is to repair by steel sleeve with composite filling[1-4].

The steel repair sleeves can be used for permanent repairing of high pressure gas pipeline defects without interrupting. With using these repair methods, we can repair defects, such as internal and external corrosion, gouges, dents, grooves, arc burns, cracks, defective girth welds, laminations and leaks $[1,2,3]$.

The steel sleeve is composed of segmented steel casing, fitted on two steel distance rings, which defines the space between the sleeve and the repaired pipe (Fig. 1.). This space

\footnotetext{
* Corresponding author: radoslav.konar@fstroj.uniza.sk

Reviewers: Josef Soukup, Tomasz Domański
} 
is filled with glass beads and epoxy (composite). When epoxide cured, provide a perfect transmission of stresses from pipeline to sleeve, while an equal stress distribution in the pipeline and sleeve $[4,5]$.

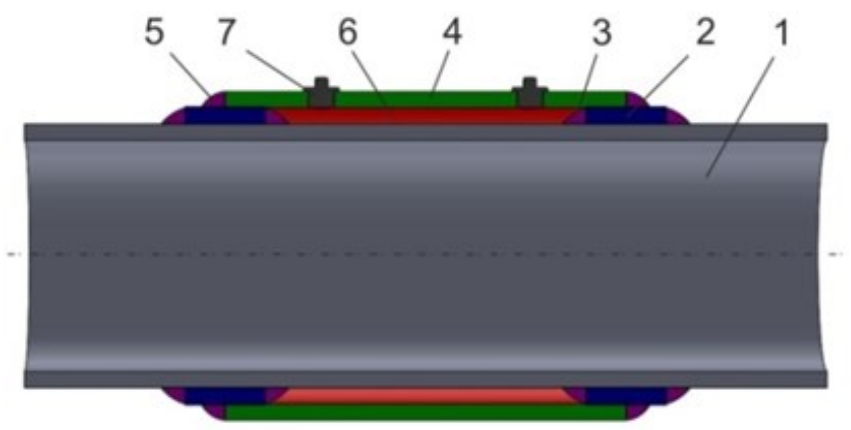

Fig. 1. Section of the gas pipeline at repair of gas pipelines with using steel sleeves with composite filling ( 1 - repairing gas pipelines, 2 - distance rings, 3 - circumferential fillet weld between distance ring and gas pipeline, 4 -steel segmented sleeve, 5 - circumferential fillet weld between distance ring and steel sleeve, 6 - composite filling, 7 -inspection holes) [4]

\section{Architecture of simulation software Sysweld}

Sysweld integrates effects linked to metallurgical transformations in the thermal, mechanical and hydrogen diffusion analysis process. Simulation is broken down into a number of successive steps due to the modular aspect of the product. Fig. 2. illustrates interaction between the various modules, with the two principle modules shown shaded. Two supplementary modules are included in the figure $[1,5,6]$.

Simulation is consequently conducted in a number of successive steps (with the results of one step forming input data for the following step):

- thermal and metallurgical computation (determination of thermal cycles and metallurgical phase proportions according to space and time),

- mechanical computation (stresses and residual strains),

- computation of hydrogen diffusion, integrating the effect of temperature, stresses and traps (reversible or inreversible).

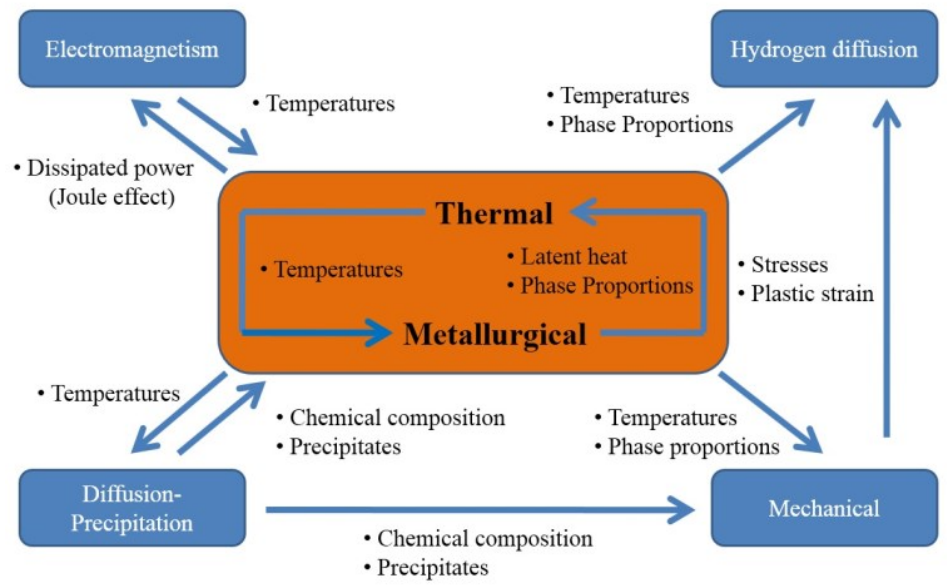

Fig. 2. General architecture of SYSWELD [4] 
In principle, a finite element simulation of the welding process consists of two main parts: thermal analysis and mechanical stress analysis. In thermal analysis, the temperature field is determined as a function of time for each integration point. This temperature timehistory is used as an input into the thermal stress analysis. Herein, the thermal solution can be sequentially or fully coupled with the mechanical solution of the structure. Because the rate of heat generation due to mechanical dissipation energy can be neglected in the heat transfer analysis, a sequentially coupled thermal-stress analysis is commonly applied for the simulation of a welding process in which a thermal analysis is followed by a stress analysis.

\section{Experimental sample and analysis of boundary conditions}

Experimental part of this article describes analysis of boundary conditions for the welding simulation at the repair of gas pipelines with steel sleeve and simulation of welding using this boundary condition for all welds.

Experimental sample (Fig. 3.) was composed of pipe and distance ring of materials L360NB in compliance with standard EN 10208-2 (WNr. 1.0582). In Tab. 1. is listed chemical composition of this material. Diameter of pipe is $323.9 \mathrm{~mm}$, pipe thickness $10 \mathrm{~mm}$ and length $970 \mathrm{~mm}$. Diameter of distance ring is $333.9 \mathrm{~mm}$, ring thickness $10 \mathrm{~mm}$ and length $90 \mathrm{~mm}[4,8,10]$.
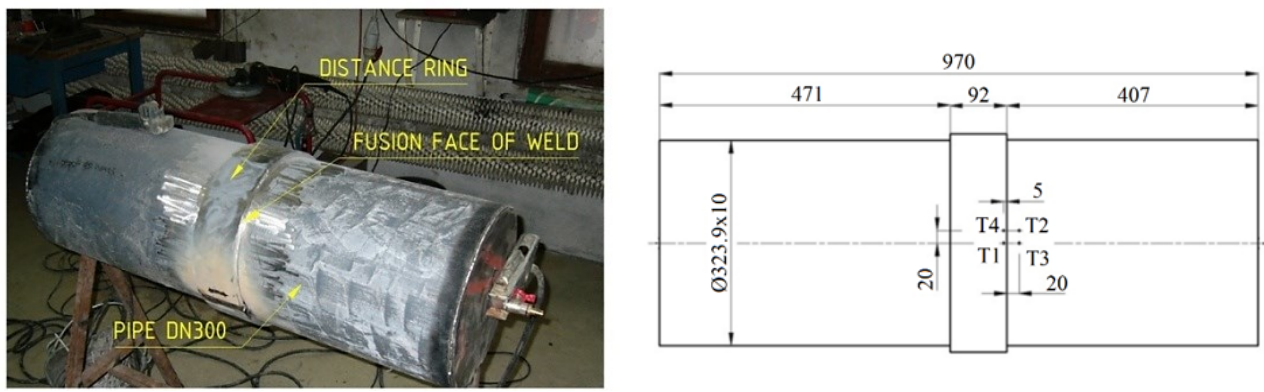

Fig. 3. Experimental sample, real sample (left), scheme with thermocouples location (right)

MMA process was used for weld joint. The filler material was coated electrode ESAB OK 48.00 , which chemical composition is $0.06 \% \mathrm{C}, 0.50 \% \mathrm{Si}, 1.20 \% \mathrm{Mn}$. Experimental sample was welded by one all around weld, which contains 6 weld beads $[4,11]$.

Table 1. Real chemical composition of steel L360NB in weight $\%$

\begin{tabular}{|c|c|c|c|c|c|c|c|}
\hline $\mathbf{C}$ & $\mathbf{S i}$ & $\mathbf{M n}$ & $\mathbf{P}$ & $\mathbf{S}$ & $\mathbf{V}$ & $\mathbf{N b}$ & $\mathbf{T i}$ \\
\hline 0.150 & 0.420 & 1.380 & 0.018 & 0.017 & 0.008 & 0.003 & 0.002 \\
\hline $\mathbf{A l}$ & $\mathbf{N}$ & $\mathbf{C u}$ & $\mathbf{N i}$ & $\mathbf{C r}$ & $\mathbf{M o}$ & $\mathbf{V}+\mathbf{N b}+\mathbf{T i}$ \\
\hline 0.025 & 0.008 & 0.060 & 0.030 & 0.070 & 0.010 & 0.112 \\
\hline
\end{tabular}

During welding were measured welding parameters, welding time and thermal cycles in four points. After welding the weld was analysed. Complete analysis of weld for simulation in simulation programme SYSWELD contains:

- parameters of welding $\mathrm{U}_{\mathrm{w}}, \mathrm{I}_{\mathrm{w}}$ and $\mathrm{v}_{\mathrm{w}}$,

- cross-sectional geometry of the welds (weld metal, heat affected zone),

- hardness of the weld,

- temperature cycles.

Two samples for macrostructural analysis (Fig. 4.) were taken from finished weld. Macrostructure not presented defects of weld. Digitized weld macrostructures (Fig. 4.) were created from cross-sectional parameters of welds in graphic programme AutoCAD. 
Parameters are necessary for the definition geometrical parameters of Goldak heat source model penetration and width of weld $[4,5,12]$.
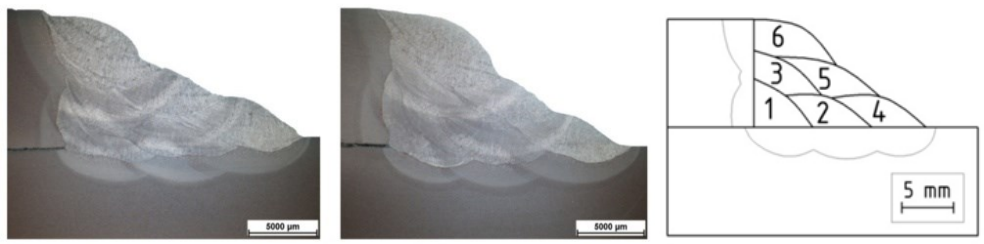

Fig. 4. Macrostructural analysis (left) with final digitized macrostructure (right)

Hardness of weld joint was measured by Vickers. The Vickers hardness profile of the weld was measured in solitary point in compliance with standard STN EN ISO 6507 (Fig. 5.). Hardness of all measured location of weld is listed in the table of the Fig. 5. Hardness of weld joint is about $230 \mathrm{HV}$, hardness of HAZ is about $200 \mathrm{HV}$ and hardness of the base material is about $185 \mathrm{HV}[4,9,12]$.

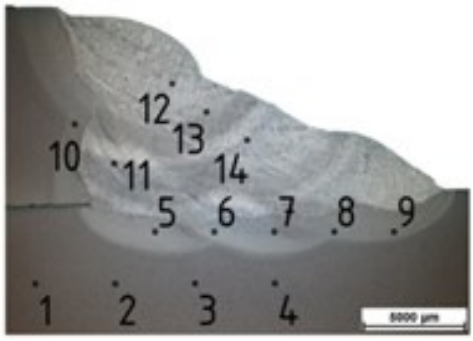

Fig. 5. Hardness of weld joint by Vickers

Table 2. Hardness of measured locations of weld

\begin{tabular}{|c|c|c|c|c|c|c|c|c|c|c|c|c|c|}
\hline \multicolumn{14}{|c|}{ Hardness by Vickers [HV10] } \\
\hline \multicolumn{4}{|c|}{ Base material } & \multicolumn{6}{|c|}{ Heat affected zone } & \multicolumn{4}{|c|}{ Weld metal } \\
\hline 1 & 2 & 3 & 4 & 5 & 6 & 7 & 8 & 9 & 10 & 11 & 12 & 13 & 14 \\
\hline 188 & 184 & 184 & 185 & 201 & 204 & 197 & 197 & 196 & 189 & 247 & 232 & 230 & 232 \\
\hline
\end{tabular}

\section{FEM simulation of welding in Sysweld}

For simulation process in programme SYSWELD was used 2D rotational model. Axis of rotation was y-axis. The model and experimental sample had the same geometrical dimensions - distance ring, welds. Length of experimental model for simulation was reduced to $300 \mathrm{~mm}$ in order to reduce computational time. Programme VisualMesh is designed for meshing 2D/3D geometrical models. In this programme was created preparation and distribution of geometrical model to FEM mesh. Meshed FEM model is shown on the Fig. 6. Distribution model has 1966 finite elements and 2885 nodes. The smallest element used in the FEM model is in the area of the weld with the dimension of $1.0 \mathrm{~mm} \times 1.0 \mathrm{~mm} \times 1.5 \mathrm{~mm}[4,5,7]$. 

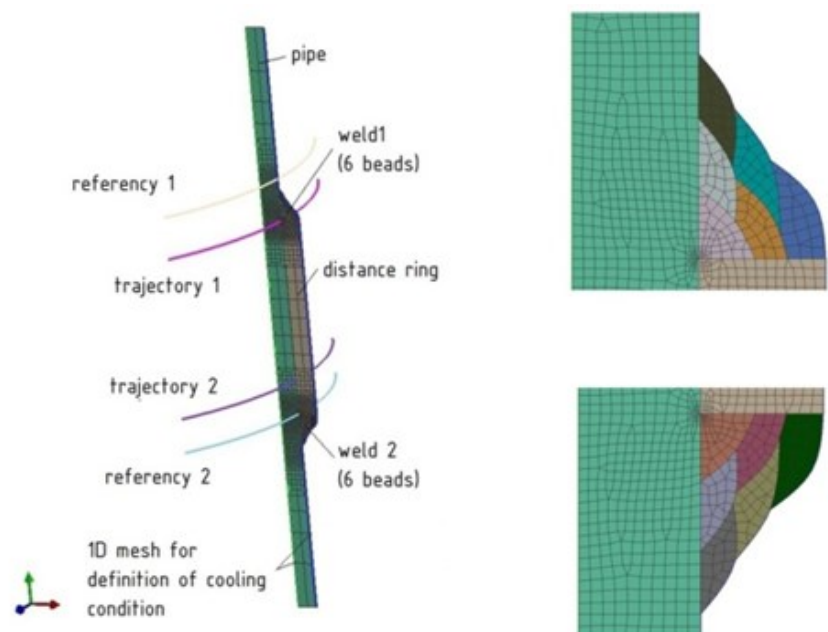

Fig. 6. 2D rotational FEM meshed model fol simulation

Material of experimental sample was steel L360NB. We could use database S355J2G3, because both of steels have the same mechanical and physical properties. Parameters of Goldak model and welding speed are in Tab. 3.

Table 3. Parameters of Goldak model

\begin{tabular}{|c|c|c|c|c|c|c|}
\hline Bead & $\mathbf{a}[\mathbf{m m}]$ & $\mathbf{b}[\mathbf{m m}]$ & $\mathbf{c}_{\mathbf{1}}[\mathbf{m m}]$ & $\mathbf{c}_{\mathbf{~}}[\mathbf{m m}]$ & $\mathbf{Q}[\mathbf{W}]$ & ${ }_{\mathbf{s w}}\left[\mathbf{m m}_{\mathbf{6}} \mathbf{s}^{\mathbf{- 1}} \mathbf{]}\right.$ \\
\hline 1 & 3.2 & 4.0 & 2.0 & 4.0 & 800 & 1.6 \\
\hline 2 & 6.5 & 2.0 & 2.0 & 4.0 & 1250 & 1.6 \\
\hline 3 & 4 & 3.0 & 2.0 & 4.0 & 2700 & 1.6 \\
\hline 4 & 12 & 2.0 & 2.0 & 4.0 & 1300 & 1.6 \\
\hline 5 & 10 & 3.0 & 2.0 & 4.0 & 1850 & 1.6 \\
\hline 6 & 1.5 & 9.0 & 2.0 & 4.0 & 2400 & 1.6 \\
\hline
\end{tabular}

S355J2G3 CCT diagram is illustrated on Fig. 7. Red curve (Fig. 7.) shown cooling rate used for simulation. Cooling rate was set to $\mathrm{q}=30 \mathrm{~W} \cdot \mathrm{m}^{-1}$.

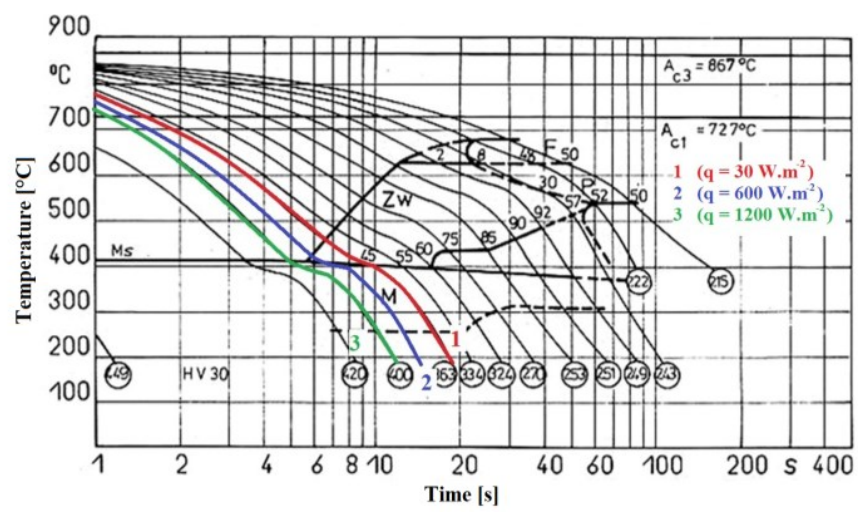

Fig. 7. CCT diagram for steel S355J2G3

Temperature fields, temperature cycles, residual stresses and hardness were simulated in the simulation for both of weld. Each weld was consists from 6 weld bead. Graphic results of temperature cycles of the simulation for finished weld are on the Fig. 8 [4, 9]. 


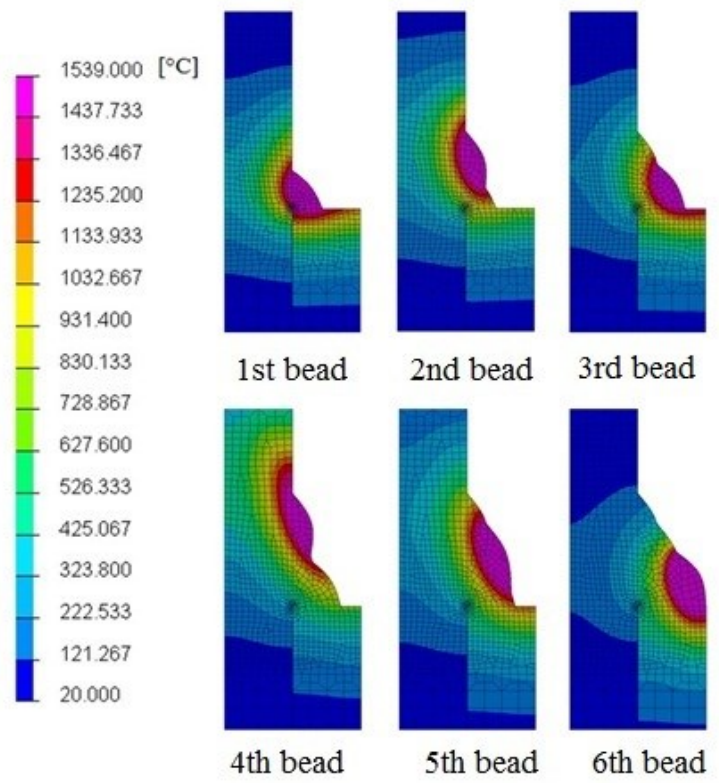

Fig. 8. Simulated temperature fields of weld

Residual stresses were only simulated, not measured. Longitudinal, transversal and reduced stresses by Von Mises were computed. The reduced stresses by Von Mises are illustrated on Fig. $9[4,8]$.

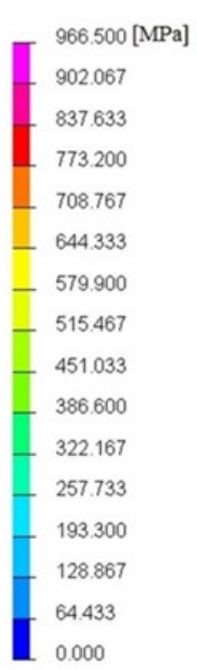

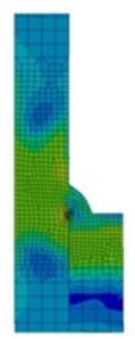

1st bead

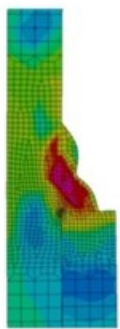

4th bead

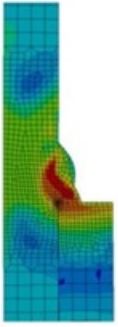

2nd bead

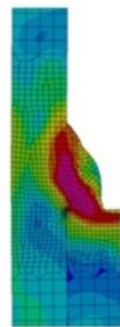

5 th bead

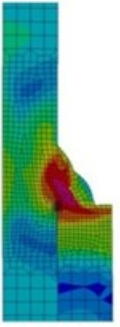

3rd bead

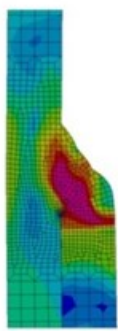

6 th bead

Fig. 9. Reduced simulated stresses by Von Misses theory

The model was rotational about the axis y and symmetrical about the centre of distance ring (plane XZ), therefore the results of residual stresses for weld 1 and weld 2 are same. Calculation of hardness by Vickers (Fig. 10.) depends on the proportion of structural phase. Hardness was computed for the finished weld joint, which contained two welds [4]. 

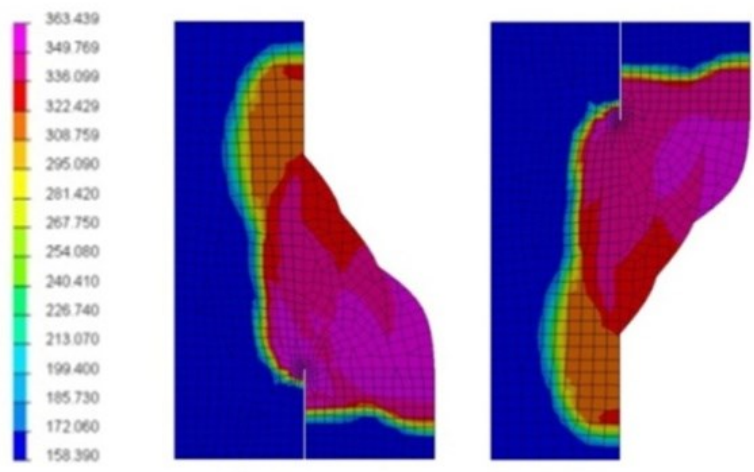

Fig. 10. Simulated hardness by Vickers [4]

\section{Conclusion}

Information about repair of gas pipeline with steel repair sleeves and welding simulation in programme SYSWELD are included in the theoretical part of this article. Experimental part describes analysis of boundary conditions and simulation of welding at the repair of gas pipelines with steel sleeves. From this information was simulated process of welding for both 6 beads welds. Results of simulation process provide information about temperature fields, temperature cycles, residual stresses and hardness of weld joint. Values of residual stress have not been verified by measurement, therefore they are only approximate.

Welding simulation has become a strong tool in technological praxis. It helps efficiently to solve complex problems in welding in a relatively short time. This article is intended as an example of welding numerical simulation capabilities in the programme SYSWELD.

This work has been supported by the Scientific Grant Agency of the Ministry of Education of the Slovak Republic, grant KEGA: 034ZU-4/2015.

\section{References}

1. A. Joseph, et al., Evaluation of residual stresses in dissimilar weld joints. International Journal of Pressure Vessels and Piping 82, 700-705 (2005)

2. G. Totten, M. Howes, T. Inoue, Handbook of Residual Stress and Deformation of Steel. (AMS International, USA, 2002)

3. J. Moravec, Influence of Welding Parameters on Weld Pool's Geometry in Shielding Gas Welding. (Pollypress, Liberec, 2011)

4. R. Koňár, et al., Finite Element Modeling and Numerical Simulation of Welding at the Repair of Gas Pipelines with Steel Sleeve. Manufacturing technology: journal for science, research and production, 16, 360-365 (2013)

5. R. Koňár, M. Patek, Numerical simulation of dissimilar weld joint in SYSWELD simulation software. Technical gazette 24, 137-142 (2017)

6. P. Novák, J. Meško, M. Žmindák, Finite element implementation of multi-pass fillet weld with phase changes. Manufacturing technology : journal for science, research and production, 13, 79-85 (2013)

7. J. Winczek, et al., Analysis of thermomechanical states in single-pass GMAW surfaced steel element. AIP Conference Proceedings 1822, 1-13 (2017) 
8. M. Brezničan, P. Fabian, J. Meško, M. Drbúl, The simulation of influence of quenching temperature on properties of bearing rings. Manufacturing technology: journal for science, research and production 13, 20-25 (2013)

9. J. Winczek, T. Skrzypczak, Thermomechanical states in arc weld surfaced steel elements with heat of melted electrode material taken into account. Archives of Metallurgy and Materials 61, 1277-1288 (2016)

10. E. Krivoš, R. Pastirčák, R. Madaj, Effect of technological parameters on the quality and dimensional accuracy of castings manufactured by patternless process technology. Archives of metallurgy and materials 59, 1069-1072 (2014)

11. P. Jankejech, P. Fabian, J. Bronček, Y. Shalapko, Influence of tempering on mechanical properties of induction bents below $540^{\circ} \mathrm{C}$. Acta Mechanica et Automatica 10, 81-86 (2016)

12. J. Winczek, The analysis of stress states in steel rods surfaced by welding. Archives of Metallurgy and Materials 58, 1243-1252 (2013) 